\title{
Correction to: Factorials Experiments, Covering Arrays, and Combinatorial Testing
}

\author{
Raghu N. Kacker • D. Richard Kuhn • Yu Lei •
}

Dimitris E. Simos

Published online: 10 May 2021

(C) Springer Nature Switzerland AG 2021

Correction to: Math. Comput. Sci. https://doi.org/10.1007/s11786-021-00502-7

In the original article, the duplicate of D. R. Kuhn was removed and replaced with Plackett and Burman before [97] and deleted ")" after [97].

Publisher's Note Springer Nature remains neutral with regard to jurisdictional claims in published maps and institutional affiliations.

The original article can be found online at https://doi.org/10.1007/s11786-021-00502-7.

R. N. Kacker · D. R. Kuhn

National Institute of Standards and Technology, Gaithersburg, MD 20899, USA

e-mail: raghu.kacker@nist.gov

D. R. Kuhn

e-mail: d.kuhn@nist.gov

Y. Lei

University of Texas at Arlington, Arlington, TX 76019, USA

e-mail: ylei@cse.uta.edu

D. E. Simos $(\square)$

SBA-Research, 1040 Vienna, Austria

e-mail: dsimos@sba-research.org 